\title{
HEAT TRANSFER EDUCATION: KEEPING IT RELEVANT AND VIBRANT
}

\author{
Ali M. Khounsary \\ Argonne National Laboratory \\ Argonne, IL 60439 \\ James R. Mondt \\ JR Engineering \\ Fort Collins, CO 80528 \\ Terry Simon \\ University of Minnesota \\ Minneapolis, MN 55455
}

\author{
and Panelists \\ Dereje Agonafer \\ IBM Corporation, Poughkeepsie, NY 12601 \\ David P. DeWitt \\ Purdue University, West Lafayette, IN 47907 \\ Richard S. Figliola \\ Clemson University, Clemson, SC 29634 \\ William L. Grosshandler \\ NIST, Gaithersburg, MD 20899 \\ Frank Kreith, P.E. \\ Boulder, CO 80302
}

\section{ABSTRACT}

The motivation for a fresh look at heat transfer education, both in content and in methodology, is generated by a number of trends in engineering practice. These include the increasing demand for engineers with interdisciplinary skills, rapid integration of technology, emergence of computerized and interactive problemsolving tools, shortening time of concept-to-market, availability of new technologies, and an increasing number of new or redesigned products and processes in which heat transfer plays a part. Examination of heat transfer education in this context can be aided by considering the changes, both qualitatively and quantitatively, in the student, educator, and researcher populations, employment opportunities, in the needs of corporations, government, industry, and universities, and in the relevant technical problems and issues of the day.

Such an overview provides the necessary background for charting a response to the difficult question of how to maintain excellence and continuity in heat transfer education in the face of rapid, widespread, and complex changes. The present paper addresses how to make heat transfer education more relevant and stimulating. This paper represents a written summary of a 1996 panel discussion at the 1996 International Mechanical Engineering Conference and Exhibition (IMECE) of the American Society of Mechanical Engineers (ASME) in Atlanta, Georgia, on "Heat Transfer Education: Keeping it Relevant and Vibrant," with significant expansion and amplification by the authors and the panelists in the 1997-98 period.

The consensus of the participants is that the steps necessary to ensure the desired outcome in heat transfer education should include: (1) a better understanding of the interaction between the student, course content. and market needs; (2) an appreciation of the need in multidisciplinary industrial environments for engineers trained with a broad background; (3) a revision of the introductory heat transfer course to incorporate illustrative and insightful industrial examples and case studies reducible to orderof-magnitude analyses; (4) a reinforcement of real-world problemsolving abilities in students by introducing them to examples that emphasize multidisciplinary issues in modern thermal management problems; and finally (5) industrial collaboration that would provide the educator with meaningful thermal management case studies (and possible funding), the student with an appreciation of industrial practices, and the industrial sponsor with access to academia for assistance in problem solving. Also suggested is an effective regular review program to provide assessment, feedback, and suggestions for quality control to interested institutions on their teaching methodology and materials.

\section{INTRODUCTION}

For the past several decades, heat transfer has been an important component of an engineering education. Many mechanical engineering departments have extensive thermal science programs, which include heat taansfer. The level of student participation in heat transfer education ranges from taking one or two courses to participating in a wide range of courses and other activities, including heat transfer senior design projects. undergraduate research, and, in the case of masters and doctoral students, extensive graduate research in heat transfer.

Although these programs have been in place for about 50 years, they are continually under review. The main motivating factors for a fresh and comprehensive evaluation of heat transfer education are rapid and pervasive changes in technology. applications, products, tools, student population, and the economy. These changes will affect research needs and priorities. funding, and eventually that which is taught in the classrooms and investigated in the laboratories. Understanding these changes and

The submitted manuscript hes been creall by the University of Chicago as Operator. Argonne National Laboratory ("Argonnt under Contract No. W-31-109-ENG-38 wı the U.S. Depanment of Energy. The U : Government retains lor lisell, and olhers at ing on its behall, a paid-up. nonexclusin irrevocable worldwide license in sato ani: to reproduce. prepare derivalive works a tribute copies to the public, and partorm il. licly and display publicly. by of on bulial the Government 


\section{DISCLAIMER}

This report was prepared as an account of work sponsored by an agency of the United States Government. Neither the United States Government nor any agency thereof, nor any of their employees, make any warranty, express or implied, or assumes any legal liability or responsibility for the accuracy, completeness, or usefulness of any information, apparatus, product, or process disclosed, or represents that its use would not infringe privately owned rights. Reference herein to any specific commercial product, process, or service by trade name, trademark, manufacturer, or otherwise does not necessarily constitute or imply its endorsement, recommendation, or favoring by the United States Government or any agency thereof. The views and opinions of authors expressed herein do not necessarily state or reflect those of the United States Government or any agency thereof. 


\section{DISCLAIMER}

Portions of this document may be illegible in electronic image products. Images are produced from the best available original document. 
continuously evaluating them would allow the educators, researchers, engineering school leaders, and policymakers to meet these changes by taking appropriate, timely, and responsive measures to ensure continued relevance and excellence in heat transfer education.

In the present engineering environment, heat transfer plays an integral, but rarely insular, role. Heat transfer is rarely practiced as taught in the classroom, and. consequently, heat transfer graduates are not always prepared to solve real engineering problems. This issue and its possible remedies are discussed in detail in the following sections. One way to summarize the issue is to assert that what ought to be taught, whether to a general engineering student or to a student specializing in heat transfer, is thermal management skills rather than heat transfer per se. A practicing engineer must have a reasonable understanding of design, analyses, materials, fabrication processes, etc., in order to be able to apply heat transfer know-how to the problem at hand. Thus, the goal of educators should be to equip students with thermal management skills that include, but are not limited to, heat transfer fundamentals and equations. The role of educators is to teach students the art of making sound engineering decisions, which begins with a systemic look at problems. An appropriate curriculum devised around this theme allows many pieces of the puzzle falling into place. For example, it would follow that the educator must be familiar with some relevant and current applications in order to use them effectively as classroom examples. Motivation to learn is enhanced and thermal management skills are sharpened when heat transfer is taught in the context of practical, current, and realistic problems rather than idealized or abstract problems. Such an approach is a challenge to many educators but will prepare the student to be more capable of meeting the demands of the industrial marketplace and more successful in engineering practice.

\section{HEAT TRANSFER EDUCATION: ASSESSMENT OF THE PROBLEM}

One objective of engineering education is to develop a level of subject mastery suitable for solving practical problems. In this regard, an assessment of undergraduate heat transfer education suggests that we take a close look at the coupling between the needs of the profession and the skills of the students being educated. Engineers are problem solvers and designers. They develop devices that interact with other devices within a system. Engineering graduates must strive to appreciate and have a broad perspective of the system under consideration, have the skills to conceive, analyze, design, and fabricate $i t$, and be able to communicate effectively within a team and within the corporate environment. In this sense, education in heat transfer is no different than in any other technical discipline. Heat transfer education should be oriented toward preparing an individual 10 meet these needs.

The subject content of an undergraduate heat transfer course is now well established. The typical undergraduate heat transfer syllabus and text book content were already chartered by the late 1950s (Kreith. 1958). A review of texts from that time to the present provides some observations. As heat transfer engineering matured, the corresponding material in the undergraduate textbooks expanded. Numerical analy'sis tools were introduced. while very little material was actually dropped. And so. texts have nearly doubled in page count over 40 years. Positive additions 10 content were improvements in pedagogy. The presentation of the material has continuously improved over time, making it more comprehensible to a broader class of students. To minimize the pattern recognition approach to problem solving, most newer texts provide design-type and open-ended problems involving physical solutions. The practice of heat transfer is often design specific. Typically, broad topical coverage of heat transfer courses can impede a mastery and appreciation of the physical and multi-mode nature of heat transfer problems, particularly when involving systems integration. This impedes development of good design skills because mastery of fundamental concepts at a reasonable level is required. The connection between course content and the manner in which students develop sound analytical and design skills must be evaluated.

Many of today's students have been raised with considerable exposure to television and computers. As such, they may be more inclined to assimilate information from visual cues better than through black-and-white text. Many students have no practical experience with mechanical hardware, yet their mathematics and physics bases are acceptable, and for the most part they have a very good aptitude for computer software tools. Accordingly, they have little appreciation for line drawings and have difficulty getting a physical feel for sizes and for material property values. Many, when exposed to visual formats and hands-on problems, respond quickly and positively. For this reason, some schools are now implementing 'Discovery' laboratories for hands-on experience with devices and systems (e.g., Figliola, 1997).

The designers of engineering education are now responding to the above with an attempt to integrate science and design but within a format that students can easily assimilate. Manufacturing is becoming recognized as an important component of design. Basic machine skill education and reverse engineering labs are being introduced to expose students to engineered products. For example, few 19-year olds have ever thought about the design and manufacturing of a heat exchanger. More emphasis on using simulation and visualization tools will allow the students to explore the cause and effect of property magnitude changes. Ten years ago, this was awkward to do, but today it is possible and is being done at a few schools.

Certainly, the university needs to be preparing students for a life-long career that will see new methodologies introduced and implemented. In this regard, the university appropriately tends to produce an engineer well grounded in engineering science. Integration of science and design is still evolving. Currently, there is too little exposure to hear transfer design in manufacturing. In a broader sense, such issues as reduction in product design and manufacturing times and effective communication are rarely addressed. Training in team dynamics should be recognized and emphasized. as it is very important for engineers destined to work in teams in industrial settings.

Improving heat transfer education requires collaboration and free exchange of ideas between universities and industry as partners. Significant changes in delivery methods and curriculum content are underway at universities to meet the needs of the student and industry. It is important that industries become involved and be active in education. Recognizing that, in a fouryear program a student will not master all the skills expected or required by an employec. industry must look 10 continuing 
education, and the professional societies must play an active role in providing professional development for life-long learning.

\section{HEAT TRANSFER, THERMAL ENGINEERING, AND THERMAL MANAGEMENT}

The traditional undergraduate course in heat transfer often begins by deriving heal conduction and convection equations (with lesser emphasis on radiation) and proceeds to applying simple techniques for solving the governing equations analytically. Since most formulations are not amenable to analytical solutions, numerical solutions along with correlations are presented.

In industry, the emphasis is on an interdisciplinary team approach to problem solving. Heat transfer engineers, for example, will team up with other engineers in the early phase of product development. Heat transfer engineers who lack a broad background or systemic approach to problem solving may not be prepared to provide sufficient input during this design phase and so thermal aspects of the design may be inadequately addressed. This situation is undesirable because addressing thermal management issues will become more difficult as the projects proceed along the design path. A heat transfer engineer would be more effective if, instead of having pure heat transfer courses, they had acquired skills taught in thermal management courses. Such courses would contain the traditional heat transfer course content but with a shift in emphasis. Elaborate mathematics, such as the separation-of-variables technique in solving multi-dimensional heat conduction equations, or meticulous derivations, such as the multi-dimensional energy equations, would be reduced. Such information is rarely used in practice and in fact tends to obscure, rather than reveal, the simple underlying physics in the problem. The emphasis should be on simple yet realistic problems in which the student can appreciate both the physics and the elegance of simple mathematics in addressing complex physical phenomena. Mathematical software packages, such as MATHCAD and Mathematica, are available to aid students in the solution of classical heat transfer problems.

The time released by a lesser emphasis on mathematics could be used to teach heat transfer as a thermal management course. A thermal management course will cover issues of practical importance in development, design, and fabrication of systems involving heat transfer. It may include topics such as material properties and compatibility, manufacturing, thermal stress, thermal fatigue, corrosion, quality control, etc. This would better prepare students for working in an interdisciplinary environment. For example, heat transfer in electronic packaging focuses typically on computing such quantities as internal resistance, external resistance, and junction temperatures. However, the issue of resulting thermal stresses cannot be left for someone else to address. With the availability of fast digital computers and robust commercial thermal, structural, and possibly computational fluid dynamic codes, the thermal engineer should be able to address all the relevant issues. These need to be covered in the first couple of courses in thermal engineering.

Material science aspects of thermal systems is an important, yet overlooked issue. For example. direct liquid cooling of computers has not advanced to the product level in part due to a lack of understanding of material properties. Some materialsrelated aspects that must be addressed include (Sing, 1997):
- Thermal conductivity of conductive pastes; effect of polymer matrix, particle composition and size on paste theology and conductivity

- Effects of the thermal coefficient of expansion mismatch of materials in electronic assemblies

- Effect of metallurgy of joining operations, such as soldering, brazing and welding

- Understanding the short- and long-term metallurgical reactions between the low-melting-temperature solder and the materials being joined

- Performance of coatings technologies, such as anodization and electroplating

- Corrosion and its prevention in water-cooled hardware A third issue of concern is manufacturability. Using a highend IBM computer system as an example, some of manufacturability issues are (Marten, 1997):

- Bum-in tests conducted to establish the integrity of the components under various thermal conditions and cycles

- Thermal processing in furnaces used for many high temperature processes, such as in solder refold

- Standard or laser machining thermal effects

The fourth issue that needs to be addressed is the effective use of computer-aided design and analysis tools. The traditional approach of designing, manufacturing, and testing in the so-called make and break approach (in which a prototype model of a system is built and tested for meeting design objectives) gives reliable data for design. There are disadvantages, however:

- Some systems are hard to build or test

- Meeting design objectives can be time consuming

- Permutations can be very costly

- The optimal design is difficult to devise, a priori

- Measurements can be complicated and costly

- Using the data obtained for predicting effects of changes in design is difficult

Computer-aided thermal engineering (CATE), on the other hand, provides an integrated approach in which many design and manufacturing aspects can be addressed and analyzed in a common database. CATE utilizing analytical/computer models can tremendously reduce the hardware building task. Advantages include:

- Rapid generation of results, which drastically reduces the lead time for a new product and shortens cycles significantly

- Easily simulated design options, which accelerate finding an optimal design

- Cost savings because simulation is substantially cheaper than building hardware

In the past decade, great advances have been made by computational fluid dynamic (CFD) vendors. In light of this development and correspondingly attractive pricing for academia, it makes sense to utilize these codes to complement analytical methods and laboratory measurements.

In summary, it is suggested that traditional heat transfer education be supplemented by thermal management course content in which greater emphasis is placed on interdisciplinary aspects of practical and current problems. Mathematical development is 
reduced, where appropriate, to focus more on current and emerging technology applications.

\section{STUDENTS, FACULTY, AND THE MARKETPLACE: NEEDS AND MOTIVATIONS}

The role of the university, the faculty, the students, and practicing engineers is to educate graduates who are able to rapidly make notable contributions in their profession. Motivating students to spend the effort required to complete the course requirements for a degree and to look forward to a rewarding career is easier if students are cognizant about their future professional environment, needs, and challenges.

Some view students educated at universities as a product. The consumers of this product are the employers in private and government laboratories, collectively referred to here as industry.

The need for thermal engineers to solve thermal and energy problems generated in industry will always exist. The knowledge of exciting career opportunities in heat transfer represents the greatest motivation to encourage student interest in this field. The laws of supply and demand will ultimately control the number of graduates that enter a given discipline, but the quality, depth, and breadth of the educational training play an important role in career development, progress, satisfaction, and success.

It is not only the students' responsibility to become knowledgeable about career opportunities but also the responsibility of the university to market and advertise so that this information is readily available to the student. Marketing engineering graduates is primarily the responsibility of academia. Universities advertise their product by producing well-educated graduates, by publishing quality technical papers, and by participating in industrial-related projects. These industrial-related projects may be in research, product development, or process development and manufacturing processes.

Communication between practicing engineers and students is critical to the successful marketing of the graduate engineer, and the best conduit to facilitate this communication lifeline is a direct link between academia and practicing engineers. Thus, practicing engineers are responsible for maintaining liaisons with educational institutions to keep them informed about current industry needs. A formal process to accomplish this task can be initiated by educational institution by inviting selected practicing engineers to participate in the development of appropriate courses, seminars, and other activities. Many practicing engineers are willing to assist, but the invitation must come from the educational institutions.

\section{THE EVER-CHANGING SCENE}

Practicing engineers must respond to consumer demands for new products, or technical information, or priorities in the marketplace. Competition forces these to continually change.

During the past several decades, as an example. the auto industry has asked thermal engineers to address problems in heat transfer, fluid mechanics, and thermodynamic for gas turbine engines, auto heating, and air-conditioning systems, and. for the past several years. exhaust emission control systems. These problems all require a working knowledge of convection, conduction, radiation, heat exchangers, Muid mechanics, material. and thermal stresses. More recently, competition in the auto industry has demanded a much shorter lime to develop a new or improved product or process. This has resulted in a revolution in the process, now identified as simultaneous engineering, in which product development and process. manufacturing for a product are carried out in parallel, in contrast to the prior years where they were serial. When this is coupled with the consequence of computer-controlled machine tools, improved product quality demands, tightening environmental constraints, and pressure for lower cost to the consumer, a host of thermal-management issues are created that will challenge thermal engineers for years to come.

To face this challenge successfully, an ongoing dialog between the three entities of the team, student, educator, and industry, is needed. Academics should communicate with industry (e.g., practicing engineers) to be appraised of current technical needs so that appropriate course content can be provided.

\section{COURSE AND LABORATORY CONTENT}

The needs of industry are important in evaluating the content of heat transfer courses. Student experiences can be categorized in order of increasing generality as (1) researchers, (2) thermaldesign specialists, (3) mechanical engineers (ME), (4) non-ME engineers and technologists, (5) policy makers, and (6) members of the general public. Graduate college curricula are primarily focused on researchers and thermal-design specialists. Preparation of thermal-design specialists and mechanical engineers consumes most of the attention of undergraduate ME faculty, with occasional attention given to non-ME majoring students, while the needs of policy makers and the general public are rarely addressed.

Researchers and thermal-design specialists are motivated 10 learn about heat transfer because they have made a decision to enter the field. They are mathematically sophisticated and have dedicated their time to understanding the underlying physics. It is this understanding coupled with exposure to a wide range of issues in thermal management that make this group of engineers ready 10 assume their appropriate role in industry. Engineers in general also have mathematical sophistication, but their desire to pursue other technical issues necessarily reduces their motivation to gain in-depth knowledge of thermal phenomena. The course content, challenges to the instructor, and suitability of alternative teaching methods differs, depending on the targeted audience.

Considering the great positive impact on society of properly educating the policy makers and general population, there seems to be a-need for an ASME-wide (and inter-engineering society wide) study of how courses should be structured for students who would be poised to be policy makers. The current discussion. however, is limited to the course content needs of researchers, thermal-design specialists, and ME students.

A foundation in chemistry, physics, fluid mechanics, mathematics (through ordinary and partial differential equations), computer programming and thermodynamics typical of what is taught at the freshman and sophomore levels is assumed. The major objectives at this stage of educational development are 10 accomplish the following: (1) instill a basic understanding of the principles of mass and energy conservation, the distinction between equilibrium states and rate processes, and the fundamental mechanisms of heat transfer (i.e., convection. conduction. radiation, and phase change): and (2) develop an understanding of how (and why) thermal measurements are made, the errors 
associated with them, and modern experimental measurement and data acquisition methods.

In more advanced heat transfer courses. the objectives would be to develop techniques for analyzing real problems, to develop an appreciation for order-of-magnitude estimations, to formulate and solve approximate closed-form solutions. and to apply simple computer methods, commercial computer codes, and experimental measurements to decide upon a reasonable design solution. Students armed with this knowledge can tackle thermal management problems that, in addition, require consideration of materials, manufacturing, and a host of other engineering issues, including economics. Some of the necessary knowledge should be obtained from coordinated introductory courses in mechanics, manufacturing, control, and design.

The content of most heat transfer courses falls into one of the following categories: conduction, convection, radiation, heat exchangers, or experimental methods. Each of these distinct topics begins with the simplest examples, solvable by mathematical analysis, and builds in complexity. Exposure to open-ended real problems may be minimal or non-existent. Students who choose additional elective courses in the thermal sciences or who pursue a graduate degree in heat transfer may have a chance to tackle thermal management problems. For those who choose other disciplines for specialization, their educational experience may fall short of the main objectives listed above.

An alternative approach is to begin an intermediate heat transfer course with discussion of a technological problem for which thermal management is an issue. Depending upon the sophistication and interests of the students, the problems could be of general societal interest (e.g., global warming, thermal pollution of streams, storage of nuclear waste, or solar energy), or specific (e.g., boiler design, electronics cooling, manufacturing processes, building insulation). Any one of these could be used as a vehicle to demonstrate how one can reduce a complex, multifaceted issue to a problem of manageable size around which a control volume with associated energy and mass flows could be constructed. The value of order-of-magnitude analysis in arriving at the essence of the problem should be taught, as well as methods to reduce errors and uncertainties by resorting to more rigorous analyses when needed. When necessary, the student could refer to specific chapters in text books or laboratory demonstrations and be assigned constrained problems to develop their understanding, then return to the open-ended problem to refine the calculation using what they have learned. This process can be repeated, each time introducing either new phenomena, more precise ways of estimating (numerical and analytical), or a new experimental measurement. When the original order-of-magnitude analysis is adequate, or at any stage of the refined analysis, the student can begin addressing other non-thermal aspects of the problem.

A course or series of courses structured as described may require a rearrangement of material now taught in two or three different courses. Considerable effort would be required on the part of the instructor to select and adapt effective case studies unavailable in current standard heat transfer textbooks. Team teaching and experimentation among the faculty and teaching assistants (TAs) would be required. Once the course has been taught a few times and a number of real-world problems have been worked through, the burden on the instructor and TA should be similar to the existing teaching load. The biggest advantage would be that this lype of course would be in a form suitable for all categories of students. The degree of precision and mathematical rigor, as well as the number of facets of thermal management problems considered, can be based on the students' strengths. their educational level, and their interests. One could even envision a course of this type as serving to improve the communications across campus, with the mechanical engineering students providing the mathematical or experimental rigor 10 guide the decisions or assist in answering, as an example. policy questions posed to students in the social sciences, humanities. or business school.

\section{DEVELOPING REAL-WORLD PROBLEM-SOLVING ABILITY IN STUDENTS}

There is an old saying. "the more things change, the more they stay the same." At the Winter Annual Meeting of ASME in Philadelphia in 1963, a panel discussing the question of "What Should be the Modern Trends in Heat Transfer Education?" concluded, among other things, that students should be exposed 10 real-world problems and learn how to tackle them. Several decades later, we are still wrestling with the same challenge.

Incorporating real-world problems in the education of engineers is an important challenge. The first and most important task is to relate homework and exam problems to current topics. For example, utility restructuring is currently under intense discussion by the media, the government, and the engineering profession. There is not a single textbook that has an example dealing with this topic. The instructor will have to design such a problem and present it to the students.

Energy conservation is another topic of interest. This may be an easier topic around which to design a problem, and there may be some textbooks that provide examples. In general, it is preferable for teachers to devise their own examples using a current newspaper article or discussion in a professional magazine as a guide. This approach excites the students.

Having designed a real-world problem, the first step should be to ask each student to describe the problem in his or her own words. Next, the student should be asked for a schematic depiction of the problem, if possible. The third step in the process should be to write down the things that are known and the things that are unknown. The fourth step in the process should be make judicious engineering decision on systems, materials, and solution approaches, followed by attempts to formulate the problem and make an order-of-magnitude assessment of the solution.

The students should then be asked to proceed with the numerical solution using a computer, and use commercial computer programs, if appropriate. Evaluation of engineering choices, design approaches, economic considerations and auxiliary information, such as material selection, corrosion, and lifetime estimates, should be addressed at this time.

The final step in the real-world solution should be a discussion of the results, which should be carefully scrutinized by the instructor. This last step is cause for concern. College textbook publishers often insist on a complete and detailed solutions manual. explaining that without a solutions manual, the professor would have to spend time solving the problem. Since most of the time grading is the task of a teaching assistant. that person may not be able to come up with the right solution if there is no solution manual available. Unfortunately, problems suilable 
for a solutions manual are not likely to be current problems from the real world.

\section{INDUSTRIAL COLLABORATION: STUDENTS, FACULTY, FUNDING}

Improving skills in solving open-ended design problems, modifying course organization to allow for design activities, improving skills in teamwork and communications, and improving skills in using computers for solving engineering problems are all necessary for the training of today's thermal engineers. Industrial collaboration provides the opportunity to enrich such course objectives and enhance student skill building.

Collaboration with industry at a few schools has become widely practiced in the senior design course and is centered about project-type activity wherein student teams work directly on industry-generated problems. Some courses, especially those dealing with mechanical systems, employ the industry-in-theclassroom approach to enliven skill building and engineering practice experiences. The role of the industrial partners has been to give seminars on specialty topics, to coach student design teams, to provide products and equipment for study, as well as to expose students to the practice of engineering in their organization. In some instances, the industrial partners have provided financial support to cover course operating expenses that could not be afforded through the departmental budget.

At many schools, the required undergraduate heat transfer course has been expanded to include new experiences in design (Beasley and Riester, 1991; Schoenhals and DeWitt, 1994), the use of productivity tools (the microcomputer and general purpose and specialized software) (Hall, et al. 1997), and problems or projects drawn from challenging industrial applications (Bianchi, et al., 1997a). Since heat transfer is generally the third course in the thermal science sequence, following thermodynamics and fluid mechanics, the challenge should be to build on these earlier experiences and show the relevance of expanded skills to the solution of exciting industrial problems. To meet this opportunity, the role of the laboratory has been reconfigured to include skill-building experiments as well as a project-type assignment that includes elements of thermal modeling, experimentation, and design. Further, the laboratory experience should promote a broad view of thermal analysis and design, especially with respect to systems approaches.

Student reactions to such reform in learning heat transfer have been positive. Through collaboration with an industry partner, the students have had opportunities to work on real problems involving real products and processes. The students have accepted responsibility for their own learning. The students are practicing engineering by studying a client's needs, generating a solution, and reporting on results and recommendations. One of the most significant benefits to the students is growth in self confidence by making a contribution to the client industrial partner.

The motivation for industry to become so involved can be quite diverse. At one level, industry has taken partnering roles in assisting broad reform in higher education through service on department advisory committees. Some industry connections find the project experiences to be valuable opportunities for solving product or process problems. The academic-industrial interface for impacting leaching and learning is one of the most important activities in the education process and has proven successful to varying degrees at various institutions. This process can he studied, expanded. and modified as necessary. and adapted hy instructors in heat transfer.

\section{ASSESSING HEAT TRANSFER EDUCATION QUALITY'}

One of the difficulties of education is that the educators never quite know how effective they are or how they may do better. If the results of the process were a consumer product, like lawn mowers, they would have market trends to review and, if certain crucial errors were made, they would be faced with litigation.

To assess heat transfer education quality. one first must ask: What is the value added to the students? First, the students are helped through an important step in their maturation. if they are the traditional students in their early-to-mid 20s, or through a reorientation or refresher state of life, if they are more senior. Students leave with enhanced skills for conducting analyses or making design choices and an improved "feel" for what makes sense and seems right. They are told numerous stories, led through homework solutions, and accompanied in lab exercises. Assessing the quality of this, then, would be by looking at their performance relative to another group without these experiences.

Assessing a group's performance may be possible by comparing the speed with which they move into responsible positions. First, how does one know that their educational experience can be credited for their success. Perhaps a highpotential group of students is attracted to a particular educational institution because of its reputation and, in fact, received little at that institution. Their success ought not be a confirmation of the educational process at that institution. An assessment based on future success requires a long time between the educational experience and the assessment period. Much can change in the meantime.

For practical reasons, one must consider a shorter time frame. Suppose the assessment were made not on actual value added but on the potential for value added, as assessed by a review panel of sufficiently knowledgeably members who could view the process and assess the potential for improved effectiveness. This body of individuals would travel from site to site and make such an assessment. Presently, the closest mechanism to such an evaluation is the ABET review. A second review is the peer review of an instructor or program given by others within the university or college. This, and the outside panel review, are often based on a very short glimpse of the process. A third assessment is by student evaluation made near the end of each academic period. This assessment is done by students who may not have a clear sense of how they will use the results of their education. All of these reviews have shortcomings.

In a search for improvement, one returns to the panel of experts concept. How might it be improved over the ABET review, in a practical way? One improvement may be 10 , in parallel with $A B E T$, focus on the heat transfer program. Perhaps first focusing on the undergraduate offering, then the graduate program. How would this be financed? Is it reasonable to expect that the companies, labs, institutes, and agencies from which these panel members come will continue their salary and sponsor their visits? Is it reasonable to expect support from the institute hosting the visitors or from state or federal governments? That depends on the value these organizations place on proper evaluation of the quality of their heat Iransfer education. 


\section{AN ACTION PLAN}

How can the schools keep heat transfer education relevant and vibrant? First, we recognize that students are typically introduced to the fundamentals of fluid/thermal processes by giving them relevant problems and lab experiences that, by and large. prepare them to (1) do correct engineering with minimal mentoring from the beginning of their professional career and (2) build upon a solid foundation for the remainder of their career. One ought to recognize and strengthen the weaknesses, however.

For one, the education students receive is still rather narrow in scope, but the demands of their future positions are ever widening to require knowledge of multiple disciplines. Educators recognize such trends, but their response has been slow. The inertia comes from the instructors' rather narrow viewpoints, perhaps a product of the focused research they do. In addition, time limitations may make it difficult to continuously research and develop new material. Thus, it may be necessary to create a wider perspective by either widening the instructors view with industrial sabbaticals, through consulting experiences, or by complementing the instructors' offerings with visitors from industry. Better cross talk between faculty, practicing engineers, and experienced industrial leaders, as well as academic-industrial partnerships, should be encouraged. A mechanism for setting up such partnerships ought to be established. This may be an appropriate topic for future panel sessions.

Further strengthening of heat transfer education offerings comes from exchange of pedagogical ideas and techniques. These are essentially the activities that have taken place under the auspices of the ASME Heat Transfer Division, Education Committee, including panel discussions in 1996 IMECE and in 1997 NHTC sessions on innovations in heat transfer education (Bianchi, et al., 1997b), and the papers that follow in this volume. In direct support of the undergraduate heat transfer student, there continues to be student papers at the NHTCs with ever-increasing exposure and popularity.

The objectives of the ASME Heat Transfer Division Education Committee extend to supporting all aspects of heat transfer education, including short courses and continuing education, as well as the more traditional modes discussed above. It is expected that continuing education will receive attention in future sessions.

\section{SUMMARY}

Both industry and educators sense and appreciate some shortcomings in heat transfer education. Some educators individually or department-wide have begun addressing the problem. But these solutions are often local and not easily accessible by others.

While short-term solutions are needed, and the ASME Committee on Heal Transfer Education can assist in providing a channel for distribution of ideas and solutions, the Committee should take an active, longer-term view. In the long term, it seems that five tasks should be accomplished. Recognition of these tasks is not new nor novel but can provide a road map for Commiltee activities and direction.

(1) Attempt to teach heat transfer in the context of a thermal management education, particularly at the undergraduate level. with appropriate changes in course content.
(2) Develop and provide guidelines and a road map to interested thermal science programs for instituting various suggestions for improvement described in this paper including teaching method, course content, and interaction with industry and practicing engineers.

(3) Establish and institute a quality control and quality assurance program in heat transfer education, in addition to the accreditation process, which is currently the norm.

(4) Encourage and, if possible, require as a part of the quality control process, industrial participation in engineering education.

(5) Examine the proposal that engineers cannot be properly trained in four years and that an engineering degree, with a stated specialty, should be conferred on those taking four years of general engineering education and an additional year of specialized training, in this case, in thermal sciences. Such systems already exists in a number of countries, and a comparative study might be fruitful.

In summary, it is hoped that the present discussion and suggestions would lead to continuous effort by the members of the ASME Committee on Heat Transfer Education and relevant professional societies to further address the issues raised here for the benefit of all involved and for preserving excellence in heat transfer education. In order to fulfill its tasks, the ASME Committee on Heat Transfer Education would like comments, assistance, input, and participation from all interested parties. You can reach the committee by contacting any of the authors.

\section{REFERENCES}

Beasley, D.E. and J.B. Riester, "Design of Thermal Systems: A Project Oriented Approach," Proceedings of the 1991 ASEE National Conference, New Orleans, LA, June 1991.

Bianchi, M.V.A., R. J. Schoenhals, and D.P. DeWitt, "Changing the Role of the Laboratory in a Heat Transfer Course," ASME HTD-Vol. 344, 1997a.

Bianchi, M.V.A., P.M. Norris, A.M. Anderson, and A. Duncan, "Innovations in Heat Transfer Education and Student Heat Transfer Design," ASME HTD-Vol. 344, Proc. 32nd Natl. Heat Transfer Conf., 1997b.

Figliola, R.S., "Rethinking the Mechanical Engineering Laboratory," Proc. ICEE, Chicago, IL, 1997.

Hall, D.E., D.P. DeWitt, and F.P. Incropera, "A New Problemsolving Environment for Learning and Practicing Heat Transfer," ASME HTD-Vol. 344, 1997.

Kreith, F., Principles of Heat Transfer, Inst. Textbook Co.. Scanton, PA, 1958.

Marten, K., IBM Corp.. Poughkeepsie, Personal communications with D. Agonifer, 1997.

Schoenhals, R.J., and D.P. DeWitt, "Integrating Fundamentals and Industrial Applications in a Heat Transfer Course," Proceedings of the Frontiers in Education. Nov. 2-6. 1994. San Jose, CA, IEEE/ASEE, (L.P. Grayson, ed.). pp. $469-$ 472.

Sing, P.G., IBM Corp., Poughkeepsie, Personal communications with D. Agonafer, 1997.

\section{ACKNOWLEDGMENT}

This work is supported, in part. by the US Department of Energy under Contract No. W-31-109-ENG-38. 